\title{
DESENVOLVIMENTO DO PENSAMENTO REFLEXIVO EM ATIVIDADES ONLINE E A FORMAÇÃO INICIAL DE PROFESSORES DE LÍNGUAS
}

\section{Emeli Borges Pereira LUZ*}

- RESUMO: Temos como objetivo neste artigo abordar, em primeiro lugar, princípios relacionados com as tecnologias da informação e comunicação (TICs) na educação e a aprendizagem do século XXI, trazendo como foco o letramento digital, a importância das TICs na formação inicial de professores de línguas e o desenvolvimento do pensamento reflexivo no contexto online. Após discorrermos sobre alguns pressupostos teóricos, iremos apresentar uma pesquisa-ação realizada em uma Universidade Pública Federal na disciplina de Metodologia de Ensino de Inglês para fins específicos. Por fim, apresentaremos os resultados da análise de dados, coletados por meio de três instrumentos, durante um semestre de atividades online na disciplina mencionada acima e nossas consideraçóes sobre as TICs aplicadas ao ensino de línguas e a formação docente.

- PALAVRAS-CHAVE: Tecnologias da informação e comunicação na educação. Aprendizagem do século XXI. Pensamento reflexivo. Formação inicial.

Com o avanço das Tecnologias da Informação e Comunicação (TIC), estamos vivenciando um momento de transformaçóes radicais no que diz respeito à comunicação e consequentemente ao sistema educacional. Essa transição histórica alcança desde o surgimento de diferentes gêneros textuais até a maneira como a informação é produzida, divulgada e consumida (THORNE; PAYNE, 2005).

A internet alterou a maneira de se comunicar e construir conhecimento em diferentes aspectos da vida e alterou as relações laborais, acadêmicas, pessoais e sociais. As características da internet a transformam em uma poderosa ferramenta no ensino e aprendizagem de línguas com a disponibilidade de materiais autênticos, suas capacidades multimídias, sua estrutura hipermídia, seus recursos de informação, imagens, vídeos e áudios acompanhados do texto escrito, comunicação síncrona e assíncrona, networking, salas de bate-papo, grupos de discussão e aplicativos interativos e colaborativos destinados a aprendizagem de línguas.

Com a permanente adesão ao uso das TIC no ensino e aprendizagem de línguas estrangeiras, atividades online colaborativas começaram a ser integradas ao ensino de

\footnotetext{
* UFU - Universidade Federal de Uberlândia. Instituto de Letras e Linguística. Uberlândia - MG Brasil.38408-144 - emeli.luz@ufu.br
} 
idiomas com a intenção de maximizar o contato de aprendizes com a língua alvo e com as habilidades do século XXI.

Pesquisas que abordam o uso das TIC no ensino e aprendizagem de línguas demonstram as vantagens de integrá-las nas aulas de línguas; entretanto, muitos trabalhos (CRAPOTTA; GARCIA, 2007; EGBERT, 2004; FELIX, 2008; JAUREGI, 2008; MIGUELA, 2007; O'DOWD; RITTER, 2007, entre outros) comprovam que não há garantias de sucesso em projetos ou atividades envolvendo o uso de TIC e o ensino e aprendizagem de línguas estrangeiras, simplesmente por eles envolverem o uso do computador como ferramenta de mediação.

Felix (2008) se propôs a realizar uma detalhada pesquisa sobre os resultados dos trabalhos publicados envolvendo Aprendizagem de Língua Assistida pelo Computador (CALL) nas duas últimas décadas. Ele traçou um panorama de trabalhos publicados entre 1981 e 2005, analisando os pontos fracos e fortes dos mesmos. O autor concluiu que os aprendizes, de um modo geral, têm uma boa percepçâo do CALL, mas um dos temas apontados como negativo está relacionado com dificuldades tecnológicas que interferem no processo de aprendizagem. Muitas vezes, os aprendizes e professores não têm a habilidade necessária para lidar com o computador ou com os aplicativos que sáo utilizados no ensino e aprendizagem de línguas mediado pelas novas tecnologias.

Considerando as Orientaçôes Curriculares para o Ensino Médio (OCEM), publicadas em 2006, percebemos a importância que se é dada ao objetivo de preparar o jovem para as demandas da sociedade do século XXI. Relembramos também o artigo 35 da LDB (no 9.394, BRASIL, 1996), que atribui as seguintes finalidades ao ensino médio: “[...] o aprimoramento do educando como ser humano, sua formaçáo ética, desenvolvimento de sua autonomia intelectual e de seu pensamento reflexivo, sua preparação para o mundo do trabalho e o desenvolvimento de competências para continuar seu aprendizado" (COSTA, 2012, p. 912).

Para tanto, é imprescindível que tais concepçōes teóricas e práticas sejam priorizadas e incorporadas à Educaçáo Básica e que sejam fortemente representadas e praticadas nas políticas de formação continuada e inicial de professores. Segundo Jauregi (2008), para que um projeto de aprendizagem obtenha sucesso, ele precisa ser significativo para os estudantes, deve atender às necessidades de aprendizagem e respeitar as idiossincrasias dos participantes. Portanto, a literatura nos sugere que o que determina o sucesso do aprendizado de línguas estrangeiras mediado por computadores envolve a combinaçáo da presença ou falta de diversos fatores estruturais, pedagógicos, linguísticos, contextuais, sociais, institucionais, de letramento digital, de acesso às tecnologias, e do uso que os aprendizes fazem das TIC.

Temos como objetivo neste artigo abordar, em primeiro lugar, princípios relacionados com as tecnologias e a aprendizagem do século XXI, trazendo como foco o letramento digital, a importância das TICs na formação inicial de professores de línguas e o desenvolvimento do pensamento reflexivo no contexto online. Após discorrermos sobre alguns pressupostos teóricos, iremos apresentar uma pesquisa-ação (THIOLLENT, 
1986) realizada em uma Universidade Pública Federal na disciplina de Metodologia de Ensino de Inglês para fins específicos. Por fim, apresentaremos os resultados da análise de dados, coletados por meio de três instrumentos, durante um semestre de atividades online na disciplina mencionada acima e nossas consideraçóes sobre as TICs aplicadas ao ensino de línguas e a formação docente.

\section{Aprendizagem do Século XXI}

Com a expansão das tecnologias computacionais em nossas atividades diárias, a sociedade em que vivemos tem sido descrita como a "sociedade da informaçáo" por causa de sua infraestrutura essencialmente baseada nas TICS, em computadores e em sistemas comunicacionais eletrônicos (GODDARD, 2002; HONEY, 2001; POLONOLI, 2001 apud KTORIDOU; ETEOKLEOUS-GRIGORIOU, 2011).

Considerando a população conectada à Internet, o acesso à informação e à educação é imensurável, porém a maneira de tratá-la modificou-se; deste modo, devemos estar preparados para lidar diferentemente com o conhecimento, o que vem sido tratado como as habilidades do século XXI. Não podemos afirmar que existe um consenso entre os pesquisadores de quais seriam, exatamente, estas habilidades, até porque elas se modificam de acordo com as novidades tecnológicas e necessidades sociais, laborais, culturais, educacionais e etc. provindas delas.

Em uma vasta revisão de literatura, Kereluik et al (2013) investigam o tópico de aprendizagem do século XXI e identificam três grandes categorias, subdivididas em 3 subcategorias cada uma, como demonstrado na figura a seguir:

Figura 1 - Síntese de 15 estruturas de aprendizagem do século 21 em uma imagem visual.

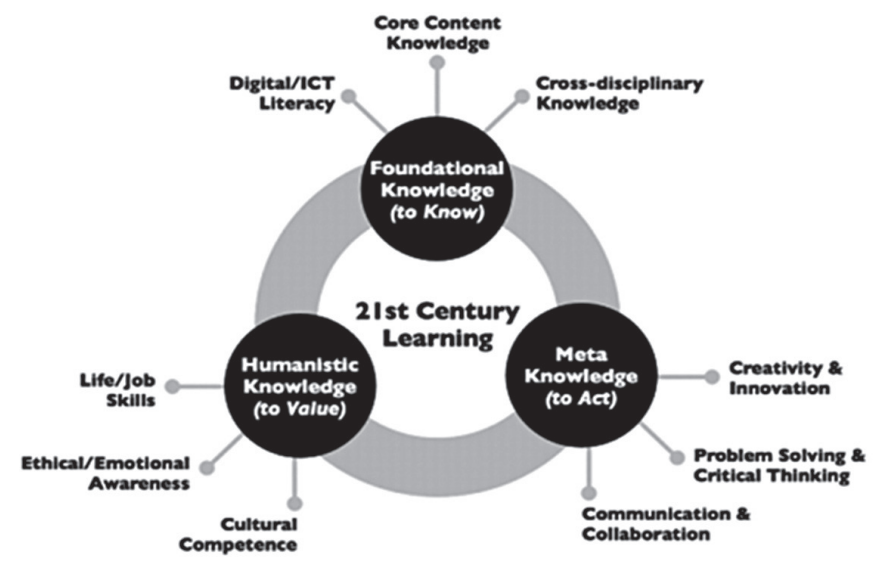

Fonte: Kereluik et al. (2013, p. 130). 
De acordo com os autores, cada categoria representa um diferente domínio de conhecimento sendo que a categoria Conhecimento Humanístico - valorizar oferece uma visão do aluno e de seu contexto social e está dividida nas subcategorias Habilidades de Vida/Laborais, Competência Cultural e Consciência Emocional/ Ética. Já a categoria Conhecimento Fundamental - saber é responsável por responder à pergunta o que os alunos precisam saber? e está subdividida em Conhecimento de Conteúdo Principal, Letramento Digital e Conhecimento Interdisciplinar. A terceira categoria, Conhecimento Meta - agir, relaciona-se ao conhecimento de processo de trabalho com a categoria Conhecimento Fundamental está subdividida em Resoluçáo de Problemas e Pensamento Crítico, Comunicação e Colaboração e Criatividade e Inovaçáo.

Neste estudo focamos nas habilidades de letramento digital e pensamento crítico/reflexivo que de acordo com o autor estão relacionadas com as categorias de Conhecimento Fundamental e Conhecimento Meta ${ }^{1}$.

\section{Letramento Digital}

Viver nesta sociedade da informaçáo é inquestionavelmente desafiador e Poore (2011) nos aponta que uma das maiores mudanças é precisamente o que está ocorrendo nos âmbitos comunicacionais, econômicos e políticos. Mas também encontramos mudanças mais culturais relacionadas com nossas tradiçóes, experiências, arte, ciência e linguagem (POORE, 2011). Para a autora, neste período de mudança, vivemos a oportunidade de adentrar um novo mundo de conhecimentos com o objetivo de contribuir com a riqueza da ética humana.

Lévy (1998), em seu livro "A Inteligência Coletiva", advoga que a riqueza depende da habilidade que temos de navegar nesse conhecimento, o que faz com que Poore (2011, p.3, tradução nossa) $)^{2}$ defenda que o letramento digital seja a chave para esta riqueza, o que "significa dar às pessoas ferramentas para se tornarem letrados digitalmente, para que elas possam viajar com sucesso pelo ciberespaço".

Para Payton e Hague (2010, p.8, tradução nossa) $)^{3}$.

\footnotetext{
O objetivo deste trabalho não é se aprofundar em todos os conhecimentos apontados pelos autores. Caso haja interesse de aprofundamento no tema sugerimos a leitura do artigo original cuja referência encontra-se no fim deste trabalho.

2 "[...] this means giving people the tools to become digitally literate so that they can successfully journey through cyberspace." Poore (2011, p.3).

3 "To be digitally literate is to have access to a broad range of practices and cultural resources that you are able to apply to digital tools. It is the ability to make, represent and share meaning in different modes and formats; to create, collaborate and communicate effectively and to understand how and when digital technologies can best be used to support these processes." (PAYTON; HAGUE, 2010, p.8).
} 
Ser digitalmente letrado é ter acesso a uma ampla gama de práticas e recursos culturais que você seja capaz de aplicar em ferramentas digitais. É a habilidade de fazer, representar, e compartilhar significado em diferentes modalidades e formatos; criar, colaborar e comunicar efetivamente e entender como e quando as tecnologias digitais podem ser melhor utilizadas para dar suporte a estes processos.

De acordo com o Centro de Desenvolvimento Educacional ${ }^{4}$, nos Estados Unidos, o letramento digital envolve uma combinação de algumas habilidades diferentes como: solucionar problemas técnicos (ou saber pedir ajuda a um técnico); usar ferramentas digitais, softwares, servidores de e-mail e ferramentas de busca e pesquisa; comunicarse online com programas de trocas de mensagens instantâneas ou através de redes sociais virtuais; usar a web para buscar informaçóes e avaliar se elas são confiáveis e precisas; ser capaz de criar e compartilhar material online (blogs, wikis, fotos, etc.) (BORAWSKI, 2009).

Muitas outras definiçóes sobre letramento digital são fornecidas na literatura com pequenas inclusóes no conceito apresentado anteriormente. Saadi (2009) descreve o letramento digital como a habilidade de conquistar resultados via computador. Warlick (2005) menciona em sua definição não somente computadores, mas também celulares, tablets e outros aparelhos eletrônicos. Outras definiçôes levam em consideração o contexto sociocultural, características da sociedade e do nosso estilo de vida (KTORIDOU; ETEOKLEOUS-GRIGORIOU, 2011).

Para Santos e Cichelero (2012, p.200):

[...] além do conhecimento funcional sobre o uso da tecnologia possibilitada pelo computador, o letramento digital implica conhecimento crítico desse uso, mediante aprendizagem de um novo tipo de discurso, o que, por vezes, assemelha-se até a aprender outra língua, conforme assevera Freitas (2010). Para esta autora há uma complexa série de valores, práticas e habilidades que constitui o letramento digital e está social e culturalmente envolvida em operar linguisticamente dentro de um contexto de ambientes eletrônicos. O letramento digital inclui, pois, leitura, escrita e comunicação.

Desta maneira, Souza (2007 apud FREITAS, 2010) classifica as diferentes definiçôes de letramento digital em dois tipos, as restritas e as amplas. Para a autora as definiçóes restritas relacionam-se mais com um uso instrumental do letramento digital e as definições mais amplas consideram o contexto sociocultural, histórico e político. Assim, após ponderar várias definiçôes de letramento digital, Freitas (2010) nos apresenta sua definiçấo do mesmo.

$4 \quad$ Educational Development Center (EDC). 
[...] compreendo letramento digital como o conjunto de competências necessárias para que um indivíduo entenda e use a informação de maneira crítica e estratégica, em formatos múltiplos, vinda de variadas fontes e apresentada por meio do computadorinternet, sendo capaz de atingir seus objetivos, muitas vezes compartilhados social e culturalmente (FREITAS, 2010, p.339).

Por conseguinte, refletindo sobre a formação de professores, Freitas (2010) defende que professores trabalhem e atuem com definiçóes mais amplas do letramento digital o que pode ajudar aprendizes a apropriarem-se crítica e criativamente da tecnologia e utilizarem-se dela de uma forma menos passiva.

Ainda considerando a formação inicial de professores de línguas, um professor digitalmente letrado pode promover uma formaçáo diferenciada a seus aprendizes, possibilitando que eles desenvolvam sua criticidade e interatividade em diferentes contextos "tornando-os sujeitos ativos no processo de construção e democratização do conhecimento" (MARZARI; LEFFA, 2013, p.4).

Deste modo, entendemos que uma das habilidades do século XXI que deve estar presente e ser trabalhada na formaçáo inicial e continuada do professor é o letramento digital, para que ele possa aplicar essa habilidade dentro de sala de aula e ajudar na formação de seus aprendizes.

\section{Pensamento Reflexivo}

Outra capacidade que deve ser trabalhada entre os estudantes para que consigam melhor desempenho e aproveitamento da avalanche de informaçóes disponíveis nos dias de hoje é o pensamento reflexivo.

A necessidade de desenvolvimento do pensamento reflexivo entre os aprendizes não é nova, ela sempre foi valorizada pelas instituiçôes educacionais. Dewey (1993), por exemplo, já nos chamava a atenção, em seu livro "How We Think", para o fato de que aprendizes deveriam refletir sobre sua aprendizagem e seus pensamentos e propôs que pensamento crítico ou pensamento reflexivo seja um dos objetivos principais da educação. Ainda mais, nos dias atuais, com o advento da internet, essa habilidade se tornou indispensável.

$\mathrm{O}$ acesso a um dispositivo conectado à internet nos possibilita infinitas oportunidades de busca e construção de conhecimento. Para tanto, é importante que desenvolvamos o pensamento reflexivo / pensamento crítico para avaliarmos a veracidade destas informaçôes e como elas se adequam as nossas concepções de mundo.

Para Kereluik et al. (2013, p.130, tradução nossa) $)^{5}$,

5 "Critical thinking frequently involves the ability to interpret information and make informed decisions based on such information. Problem solving is often conceptualized as the use of critical thinking skills toward the effective resolution of a specific problem or toward a specific end goal". (KERELUIK et al., 2013, p.130). 
O pensamento crítico frequentemente envolve a capacidade de interpretar informaçóes e tomar decisóes conscientes com base em tais informaçóes. A solução de problemas também é constantemente conceitualizada como o uso de habilidades de pensamento crítico em direção à resolução efetiva de um problema específico ou em direção a um objetivo específico.

Corroborando com estes posicionamentos, Shirkhani e Fahim (2011) defendem que o pensamento reflexivo também está relacionado com a tomada de responsabilidade pelos seus próprios pensamentos e com a capacidade de exercitar o entendimento, a avaliação em diferentes perspectivas e com a solução de problemas.

Os conceitos de pensamento reflexivo também vão ao encontro da abordagem de letramento critico bastante difundida no ensino e aprendizagem de línguas. Discutindo sob esta perspectiva, Jordão e Fogaça (2007) relatam a importância de tais práticas estarem envolvidas no ensino de línguas estrangeira e presentes na sala de aula.

O ensino/aprendizagem de línguas estrangeiras pode assim construir com os alunos uma percepção de seu papel ativo na transformação da sociedade, uma vez que a sala de aula pode ser um espaço onde se questionem as próprias visóes de mundo, onde se investiguem de onde vêm as diferentes perspectivas construídas por nós (incluindo aquelas que se supóem estejam presentes nos textos impressos) e para onde tais perspectivas podem levar, que consequências elas podem ter em nossas percepçôes identitárias e nas representaçôes que fazemos do mundo. Ao questionar pressupostos e implicaçóes de diferentes pontos de vista na sociedade - e nos textos - e assim ampliar nossas perspectivas, é possível que os alunos sejam capazes de também perceber-se enquanto sujeitos críticos, capazes de agir sobre o mundo e seus sentidos. $\mathrm{O}$ ensino de línguas estrangeiras, nesta perspectiva, objetiva um alargamento da compreensão de que as línguas são usadas de formas diferentes, em contextos diferentes com pessoas diferentes e propósitos também diversos e, desse modo, possibilitar a construçáo e o uso de procedimentos interpretativos variados no processo de construção de sentidos possíveis. (JORDÁO; FOGAÇA, 2007, p.93).

Entendemos que uma abordagem que envolva o pensamento reflexivo e o letramento crítico e digital possa gerar boas oportunidades de construção de conhecimento. Ainda considerando tais pressupostos, cada vez mais será importante que desenvolvamos habilidades de resoluçấo de problemas e de tomadas de decisóes conscientes, baseadas em informaçóes, para conseguirmos lidar com as atividades corriqueiras de nossas vidas, nos estudos, no(s) trabalho(s), na esfera social, etc. Portanto, é essencial que tais habilidades se encontrem presentes nas salas de aulas para que nossos alunos preparemse para utilizá-las dentro e fora dos âmbitos educacionais. 
Após a exposição breve de nossa fundamentação teórica, apresentaremos dados decorrentes da pesquisa-ação realizada em uma Universidade Federal no segundo semestre de 2015.

\section{Contexto da Pesquisa}

A pesquisa em questão ocorreu em uma Universidade Pública Federal, no curso de Letras, durante o segundo semestre de 2015, na disciplina de Metodologia de Ensino de Inglês para fins específicos.

Motivados pela necessidade de instigar o pensamento reflexivo e trabalhar com o letramento digital entre os alunos de Letras, ainda em sua formação pré-serviço, e com intuito de formar profissionais qualificados para atuar na sala de aula, programamos o semestre incluindo atividades online durante a extensão do mesmo. Optamos por utilizar como apoio a plataforma Edmodo ${ }^{6}$ e trabalhar com 5 atividades diferentes.

A disciplina foi organizada em 17 encontros, distribuídos em 15 presenciais e dois online onde foram trabalhas as atividades descritas abaixo. As atividades 1 e 2 foram propostas para o primeiro encontro e as atividades 3 , 4 e 5 para o segundo:

1) Construção de dois Mapas Mentais a partir de dois textos selecionados (um mapa para cada texto). A ferramenta sugerida foi o MindMeister ${ }^{7}$.

2) Discussão em Fórum de uma pergunta feita pela professora-pesquisadora, direcionada à pré-discussão de um texto.

3) Gravaçấo de Resposta Oral (podcast) relacionada a pontos levantados pela professora-pesquisadora, direcionados à pré-discussáo de um texto. A ferramenta sugerida foi o Vocaroo ${ }^{8}$.

4) Criação de uma pergunta, referente a uma leitura específica, para ser respondida por outro grupo na forma de postagem na plataforma do Edmodo.

5) Resposta à pergunta criada pelo outro grupo.

As atividades foram propostas no primeiro dia de aula, se adequando com o cronograma do semestre. Cada uma das atividades tinha um prazo determinado e conforme a proximidade de entrega das atividades a professora-pesquisadora recordava os aprendizes sobre as mesmas, as explanava novamente e se colocava à disposição para dúvidas, tanto presencialmente quanto virtualmente.

\footnotetext{
6 Para maiores informaçóes acesse <http://www.edmodo.com>.

7 Para maiores informaçóes acesse <http://www.mindmeister.com/pt>.

8 Para maiores informaçóes acesse $<$ http://vocaroo.com/ $>$.
} 
Foram enviadas aos alunos explicaçóes detalhadas de cada atividade e sugestôes de aplicativos a serem usados, juntamente com tutoriais de cada programa; ainda assim os aprendizes poderiam usar o aplicativo similar que lhes fosse mais conveniente. Todas as atividades foram postadas na plataforma Edmodo e acompanhadas pela professorapesquisadora.

Tivemos como participantes de pesquisa 17 aprendizes, sendo 10 do período matutino e 7 do período noturno, com um desistente no meio do semestre.

$\mathrm{Na}$ coleta de dados utilizamos 3 instrumentos, sendo:

1) O primeiro, um questionário impresso (doravante Q1) elaborado por uma doutoranda que fazia observaçóes de aulas para coletar dados para sua pesquisa (13 respondentes). Este questionário foi aplicado na segunda semana de aula;

2) O segundo, um questionário de análise de necessidades via formulário Google (doravante Q2) elaborado pela professora-pesquisadora (9 respondentes). Este questionário foi aplicado em novembro de 2015;

3) E, o terceiro, foram as próprias atividades postadas na plataforma Edmodo (65\% de entrega). As postagens ocorreram durante todo o semestre.

Os dados coletados nos ajudaram a refletir sobre dois aspectos que consideramos importantes na formação de professores:

- De acordo com a perspectiva dos aprendizes, qual a importância do uso de tecnologia para o professor em formação de língua inglesa?

- Este mesmo grupo desenvolve o pensamento reflexivo ao trabalhar com atividades online?

Passemos, portanto, a análise dos dados para discutirmos quais as nossas consideraçóes a respeito das perguntas propostas.

\section{Análise dos Dados}

\section{Formação pré-serviço e letramento digital}

Para darmos início a análise da primeira discussão proposta, iremos apresentar, primeiramente, as respostas a uma questáo do Q1, descrita logo a seguir:

Pergunta $1-$ Q1

Em sua opinião, durante o curso de formação de professor, aprender a usar as tecnologias digitais como recurso didático, para as aulas de língua estrangeira é:

( ) fundamental;

\footnotetext{
9 Para maiores informaçôes acesse: <https://www.google.com/intl/pt-BR/forms/about/>.
} 
( ) necessário;

( ) importante, mas não necessário;

( ) irrelevante;

( ) desnecessário.

Explique o motivo de sua escolha dentre as alternativas apresentadas.

Dentre os respondentes (13), 46,5\% responderam a primeira opção, fundamental. Atentemo-nos a um motivo apresentado ${ }^{10}$ :

Excerto $1-\mathrm{Q} 1$

Hoje todas as atividades cotidianas ou não, estão ligadas ao uso de tecnologia, portanto, cabe ao ensino também seguir essa tendência.

Ainda outros 46,5\% optaram pela segunda opção, necessário:

Excerto $2-\mathrm{Q} 1$

A cada dia que passa o mundo está mais envolvido com a tecnologia, precisamos atualizar e diversificar as formas de ensino, e essa metodologia pode favorecer tanto alunos quanto professores, tornar o ensino mais prático.

E somente um respondente, equivalente a 7\%, escolheu a terceira opção, importante, mas náo necessário, fornecendo o seguinte motivo:

Excerto 3-Q1

Os professores devem ter a habilidade de tanto ensinar por meio dos métodos tradicionais como também com o uso de tecnologias digitais.

Podemos observar que a maioria dos alunos entende que é tanto necessário quanto fundamental a prática de ensino e aprendizagem com utilização de recursos digitais na formação pré-serviço e mesmo o respondente que assinalou a opção importante, mas náo necessário, se contradiz na justificativa de sua escolha mencionando o dever dos professores dominarem o uso das novas tecnologias.

Esses posicionamentos foram confirmados nas respostas a uma pergunta similar proposta no instrumento Q2:

Pergunta 8-Q2

Qual você acredita ser a importância do uso de tecnologia na sua formação como professor de língua inglesa?

Selecionamos os seguintes excertos para discussão, provindos de diferentes aprendizes:

$\overline{10}$ Nos instrumentos de coleta de dados Q1 e Q2 os alunos nấo precisavam se identificar. 
Excerto 4-Q2

A tecnologia vem como um facilitador na preparação das aulas de LE, pois abre portas para uma variedade de atividades e novas maneiras de se ensinar; e se bem usada, desencadeia várias vantagens no ensino-aprendizado de línguas.

Excerto $5-\mathrm{Q} 2$

Acredito que elas são uma ferramenta de ensino da língua, existem professores que sabem usá-las de forma proveitosa e outros que tem uma certa dificuldade. Para minha formação elas têm sido uma novidade e às vezes custo aprender a trabalhar com elas. Creio que sem elas o ensino, não só de língua inglesa, não é mais viável.

Excerto 6-Q2

Como vivemos em um mundo globalizado e com a presença de tecnologias no nosso cotidiano, é preciso aprender a lidar com essas plataformas e ferramentas, pois a tendência é que o aluno faça uso delas em seu processo de ensino aprendizagem, e o professor precisa se adaptar.

Os dados obtidos do instrumento Q2 corroboram os dados do instrumento Q1. Ainda podemos destacar que os respondentes abordam sutilmente questôes como a necessidade do bom uso da tecnologia e a dificuldade de alguns profissionais com a adaptação e uso das ferramentas, mas dentre todas as respostas obtidas foi unânime a percepçáo da importância da presença da prática do ensino e aprendizagem com uso de novas tecnologias na formação dos respondentes, tanto como professores em formação quanto como aprendizes.

Durante a pesquisa, procuramos também buscar evidências de letramento digital dos aprendizes. Assim, propusemos a pergunta abaixo no instrumento Q2:

Figura 2 - Como você avalia a plataforma Edmodo no quesito de navegação e uso?

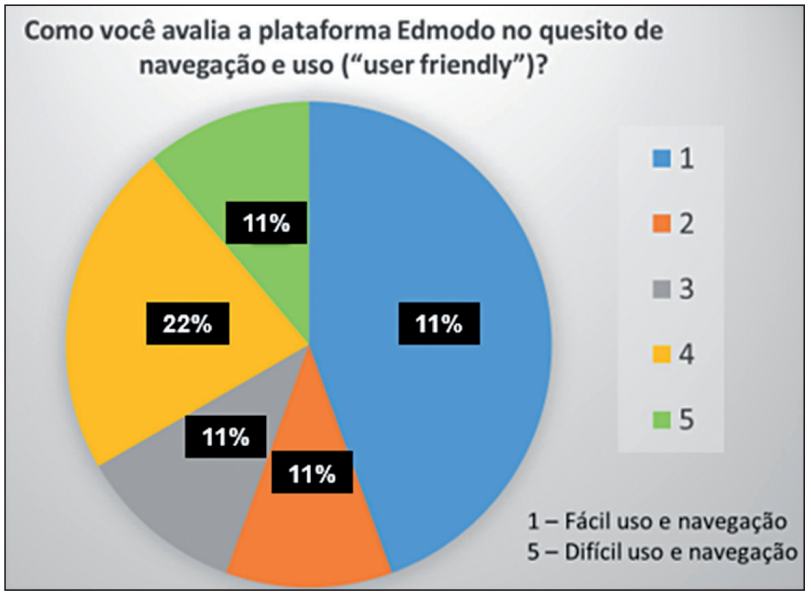

Fonte: Pergunta $1-\mathrm{Q} 2$. 
Apesar de 33\% dos alunos optarem pelos graus 4 e 5 de dificuldade sobre a acessibilidade e uso da plataforma, somente encontramos uma evidência de insegurança em relação a ela, demostrada a seguir:

\section{Excerto 7 - Plataforma Edmodo}

Hello! This is my Podcast about the questions/assumptions. I hope it works! (:

Outras questôes surgiram relacionadas com tecnologia em geral:

\section{Excerto 8 - Q2}

O mapa mental foi meio complicado acho que pelo meu computador que estava horrível...

Excerto 9-Q2

Não gostei de fazer o mapa mental porque não gostei da ferramenta, e não vejo diferença em fazer isso no papel ou online.

Identificamos que dentre os 13 respondentes do Q1, 9 respondentes do Q2 e 17 aprendizes que postaram atividades na plataforma, existiram algumas dificuldades tecnológicas que variaram entre acessibilidade e uso da plataforma (excerto 7), letramento digital (excertos 4, 5 e 9) e equipamento de trabalho (excerto 8). Entretanto náo encontramos indícios de que essas dificuldades não foram superadas. Assim, entendemos que tais contratempos são, na verdade, oportunidade de aprendizagem e construção de novos conhecimentos.

Deste modo, como entendemos que a prática de atividades tecnológicas e o letramento digital não apresentaram impedimentos na construção de conhecimento para os professores em formação, passemos a discutir o uso e desenvolvimento do pensamento reflexivo nas atividades online propostas.

\section{Pensamento Reflexivo}

Iremos dividir essa seção em duas partes com o objetivo de debater dois resultados da pesquisa. As seçóes irão apresentar dados que indicam e não indicam desenvolvimento de pensamento reflexivo durante a conclusão das atividades online sugeridas durante o semestre.

Debateremos a princípio os indícios de desenvolvimento de pensamento reflexivo.

\section{Indícios de desenvolvimento de pensamento reflexivo}

A riqueza de dados encontrados que ratificam o desenvolvimento do pensamento reflexivo entre os participantes da pesquisa é bastante considerável. Encontramos vários 
indícios de aplicação de pensamento reflexivo nas postagens na plataforma Edmodo. Comecemos pela atividade de discussão em fórum ${ }^{11}$.

Excerto 10 - Plataforma Edmodo - Atividade 2

Well, by seeing what Karina ${ }^{12}$ and Roberto said I kind of agree with their opinions, because this is a situation with two sides, and so, with two great and powerful arguments. So, I'd like to analyse it by the student's perspective, because, as a teacher, you need to focus on your students when prepare their course $[\ldots]^{13}$

Excerto 11 - Plataforma Edmodo - Atividade 2

I agree with Karina, and I think that if you're able to give for your student the capacity to understand and visualize how big and dificult is the area that you're teaching, you 'll be a good teacher [...]. (I'm having problems to express my idea about this topic, sorry $)^{14}$

Acreditamos que o resultado da atividade de discussão em fórum foi significativo. Como preparação para a atividade, foi debatido nas aulas presenciais as maneiras mais eficazes de produção de conhecimento através dessa ferramenta (fórum em ambiente virtual). A professora-pesquisadora salientou nestas conversas que o fórum é um espaço de interatividade e para que isso ocorresse os professores em formação deveriam ler as postagens dos colegas, refletir sobre elas e elaborar a sua postagem, contribuindo de forma a apresentar novas ideias e complementar os posicionamentos dos colegas.

Isso mostra-se de forma bem presente em vários momentos da discussão, como exemplo o excerto 10 em que a aprendiz cita dois outros colegas e depois propóe a sua contribuição analisando o problema trazendo duas perspectivas distintas sobre ele. Essa postura evidencia uma marca forte do pensamento reflexivo que considera mais de uma maneira de pensamento e solução de problemas.

O interessante do excerto 11 é que além da aprendiz considerar a colocação de outro colega ela se desculpa, no fim da sua postagem, pois teve dificuldades de expressar suas ideias sobre o assunto. Apesar da desculpa, a aprendiz contribuiu com um post de 487 caracteres, totalizando 7 linhas, defendendo seu entendimento sobre o assunto, o que consideramos como significativo. Mesmo tendo dificuldades, a aluna conseguiu

11 Os excertos estão apresentados da mesma forma que foram escritos na plataforma, sem correções linguísticas.

12 Nomes fictícios.

13 Tradução nossa: Bem, vendo o que Karina e Roberto disseram eu meio que concordo com suas opinióes, porque esta é uma situação que contem dois lados, e portanto, com dois grandes e fortes argumentos. Então, eu gostaria de analisá-la pela perspectiva do aprendiz, porque, como professora, você precisa focar nos estudantes quando prepara o curso deles.

14 Tradução nossa: Eu concordo com a Karina, e eu acho que se você é capaz de mostrar para seu aluno a capacidade de entender e visualizar quão grande e difícil é a área que você está ensinando, você será uma boa professora [...]. (Estou tendo problemas para expressar minhas ideias sobre este tópico, desculpas). 
concatenar suas ideias e sinalizar sua opinião na discussão, exercitando o pensamento reflexivo, dentro de suas limitaçóes.

Outro exemplo foi a confecção dos mapas mentais. De acordo com as informaçóes disponibilizadas no Portal Hipertexto da LATEC/UFRJ (Laboratório de Pesquisa em Tecnologias da Informação e da Comunicação da Universidade Federal do Rio de Janeiro),

Mapa mental é uma ferramenta de suporte ao pensamento e à criatividade. Baseiase no conceito de que nossos pensamentos não são lineares (não seguem um fluxo contínuo) e que quando usamos cores, imagens e palavras-chave nossa capacidade de criação e retenção aumenta muito. (PORTAL HIPERTEXTO, 2016).

A seguir trazemos um mapa que foi elaborado por um dos alunos para responder à pergunta "Quais as origens do Inglês para Fins Específicos no Brasil e no exterior?". A pergunta, proposta pela professora-pesquisadora, deveria ser respondida em forma de mapa mental e baseada na leitura de um texto de Dudley-Evans e St. John (1998).

Figura 3 - Origins of ESP in Brazil and abroad

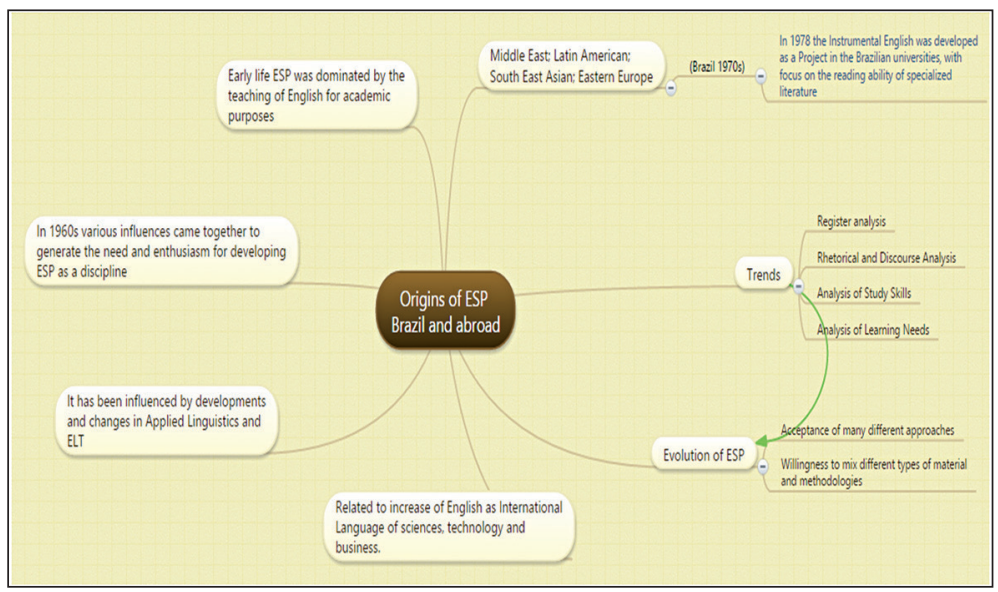

Fonte: Plataforma Edmodo / MindMister - Atividade 1.

Podemos observar que o mapa mental foi feito com muitos detalhes e conseguiu responder plenamente à pergunta apresentada. Nesta atividade, o professor em formaçáo demostra: ter lido o texto com bastante atenção (apresentou todas as questóes importantes da leitura); capacidade de sumarização de pontos relevantes (conseguiu em pequenos trechos representar a leitura); organizaçáo de pensamentos (demostrado pela organização em tópicos e pequenos parágrafos); criatividade e associação (a própria escolha de cores e a direção das setas marcam esta habilidade). Estas características são extremamente relevantes na prática de pensamento reflexivo. 
De acordo com Edward (2011), a única desvantagem do uso de mapas mentais é a resistência que algumas pessoas possam oferecer à quebra de paradigmas de um pensamento linear a que foram acostumados desde a infância. Nós entendemos que este é mais um motivo para introduzi-los na sala de aula, para que os aprendizes possam ter a oportunidade desse rompimento, sempre com a ajuda do professor como mediador.

Mais evidências de desenvolvimento de pensamento reflexivo foram apresentadas nas atividades 4 e 5 . Analisemos a amostra a seguir:

Excerto 12 - Plataforma Edmodo - Atividade 4

Pergunta para a Carla: Após a realização de sua pesquisa, o autor pontua que, de alguma forma, os resultados apontaram para uma mudança. Ele ainda diz que: '[a] credita que, sem perspectiva de mudança, professores, experientes ou não, podem náo se sentir motivados a reavaliar seu ensino, a tomar decisóes realistas ou até mesmo a compreender a função que o ensino de uma língua estrangeira realmente desempenha ao fazer nossos alunos mais conscientes de seu próprio papel como aprendizes e cidadáos.' (FIGUEIREDO, 2003, p.196). Avaliando os processos de preparação e avaliaçáo do curso apresentados durante o texto, como você acredita que esses processos e sua descrição podem auxiliar na autoavaliação de um professor sobre seu curso e sua prática?

Roberto, ao propor essa pergunta, primeiramente leu e refletiu atentamente sobre o texto. Interessante o fato dele escolher um excerto do texto que trata exatamente a questão da reflexão e autoavaliação do professor e suscitar essa reflexão também em sua colega, que teria que rever estes conceitos no texto para responder à pergunta proposta. Roberto instigou a parceira à reflexão, não só sobre o texto, mas também sobre sua própria prática atual ou futura. Este é mais um exemplo de que os aprendizes estavam desenvolvendo e praticando o pensamento reflexivo nas atividades online sugeridas.

Examinemos também os seguintes excertos, provindos do instrumento Q2.:

Excerto $13-\mathrm{Q} 2$

A discussão em fórum promoveu bastante conhecimento e apresentação de boas ideias. Gostei bastante também da participação da professora nas tarefas.

Excerto $14-\mathrm{Q} 2$

Fazer o mapa mental foi bastante divertido, e acredito que, de todas as atividades, foi a mais eficaz. Ele dá mais trabalho - você tem que ler o texto, compreendê-lo e depois montar de forma criativa o mapa - mas ajuda bastante a memorizar e entender o conteúdo. 
Excerto $15-\mathrm{Q} 2$

A criação de um mapa mental me ajudou a desenvolver as habilidades da web relacionadas ao tópico. Já a discussão em fórum foi interessante por apresentar diferentes pontos de vista e possibilitar uma interação online.

Excerto $16-\mathrm{Q} 2$

Precisei de um tempo para aprender a usar o site; no entanto, a atividade acabou dando certo no final.

Nestes excertos, conseguimos identificar depoimentos de construção de conhecimento, interação e interpretação de informação através da discussão em fórum (excertos 13 e 15) evidenciados pelos próprios relatos dos aprendizes que reconheceram que estes instrumentos lhe proporcionaram oportunidades de interação online, apresentação de boas ideias e de diferentes pontos de vista e compreensão de texto. Os aprendizes também relataram momentos de reflexão, criatividade e desenvolvimento de habilidades tecnológicas através da elaboração do mapa mental (excertos 14 e 15) ao afirmarem que fizeram a leitura e reflexáo dos textos para posteriormente construir de forma criativa o mapa. Ainda demonstraram solucionar problemas (excertos 14, 15 e 16) quando afirmaram que a tarefa foi trabalhosa e quando tiveram que desenvolver habilidades de letramento digital para completarem a mesma.

Todos estes elementos são demonstrativos de que os professores em formação praticaram o pensamento reflexivo ao trabalharem nas atividades sugeridas, interpretando informações e tomando decisões conscientes, como também usando suas habilidades de resolução de problemas.

Cada uma das atividades tinha um propósito distinto que exigia dos aprendizes diferentes habilidades e maneiras de organização de pensamento e construção de conhecimento relacionados com a disciplina em questão e também com o letramento digital.

Assim, conseguimos perceber o desenvolvimento do pensamento reflexivo dentre os aprendizes. Entretanto, também reconhecemos momentos em que a criticidade poderia ter sido melhor desenvolvida. Passemos a analisar este ponto.

\section{Indícios de não desenvolvimento do pensamento reflexivo}

Apesar de defendermos que vários alunos conseguiram demonstrar desenvolvimento do pensamento reflexivo durante as atividades online, também conseguimos identificar momentos em que uma reflexão mais crítica poderia ter sido trabalhada. Observemos o excerto a seguir: 


\section{Excerto $17-\mathrm{Q} 2$}

[...] mas acredito que o ponto fraco das atividades online foi ter sido feitas durante a semana e não no horário da aula. O prazo para postar não era nem mesmo no dia da disciplina e isso enfraquece a participação visto que todos têm outros compromissos, inclusive com outras disciplinas que sempre tem os seus afazeres em casa, como ler textos, produzir textos etc.

A proposta dos encontros virtuais surgiu, primeiramente, em decorrência de oportunizar aos professores em formação o contato com atividades online e desenvolvimento do pensamento reflexivo, mas também foi uma alternativa que a professora-pesquisadora elaborou para lidar com vários feriados que coincidiam com os dias da disciplina.

Assim, os aprendizes tiveram de duas a três semanas para compartilharem as atividades. A não obrigatoriedade de postar as atividades em um horário ou dia específico ajudaria na construção da autonomia e responsabilidade pelo próprio aprendizado de cada aprendiz. Entendemos que a aluna em questão não está familiarizada com as vantagens oferecidas pela prática do ensino a distância e ainda está enraizada aos moldes arcaicos do ensino tradicional presencial, cujos aprendizes nem sempre têm a chance de exercer sua autonomia.

Outro indício de falta de pensamento reflexivo encontra-se no próximo excerto:

\section{Excerto $18-\mathrm{Q} 2$}

Tive mais dificuldade para gravar o podcast, pois apesar das instruçóes da atividade estarem claras (que era comentar as afirmativas dadas), as afirmativas estavam confusas e similares entre si. Quanto à discussão em fórum, eu particularmente não gosto deste tipo de atividade por termos a obrigatoriedade em comentar um tópico em específico. Em alguns momentos, não temos uma opiniấo formada a respeito. Minha sugestão, neste caso, é colocar mais de um tópico em discussão.

Nos dois momentos apresentados, a professora em formação poderia ter buscado ajuda da professora-pesquisadora, que se fez disponível tanto nos momentos presenciais como também nos momentos virtuais. Ao invés da aprendiz se envolver mais profundamente com as atividades, ela preferiu fazê-las sem uma maior reflexão e aprofundamento.

No segundo caso, a proposta do fórum era realmente a questão criticada pela aprendiz. $\mathrm{O}$ intuito era a formação de opinião, a reflexão crítica sobre o assunto e a discussão em grupo para formação de novos conceitos. Deste modo, acreditamos que a passividade da aprendiz e falta de engajamento na atividade demonstrou que o pensamento reflexivo poderia ter sido mais utilizado por ela.

É essencial ressaltarmos que a formação de professores, considerando um viés críticoreflexivo, espera que o professor participe na construção de conhecimento e não seja 
somente um consumidor de teorias e práticas já existentes. Na prática da sala de aula e refletindo constantemente sobre seu contexto, público, instituição, etc., o professor deve estar em constante ponderação para adaptar a teoria a realidade de sua sala de aula, desenvolvendo, portanto, suas próprias teorias (baseadas em decisóes provinda de suas reflexôes críticas).

Passemos, portanto, as nossas consideraçôes finais.

\section{Considerações Finais}

Este artigo teve como objetivo analisar questôes relacionadas com o desenvolvimento e prática do pensamento reflexivo em atividades online em um grupo de professores em formação inicial. Duas questóes foram consideradas; a princípio a familiaridade e facilidade de uso dos aprendizes com a plataforma utilizada, relacionada com o letramento digital do grupo e a importância de atividades deste escopo estarem presentes na formaçáo de professores; segundo a aplicabilidade do pensamento reflexivo nas atividades.

Constatamos que apesar de a maioria dos professores em formação perceber a importância do uso da tecnologia em sala de aula e de muitos náo terem dificuldades de usá-las de forma a desenvolver o pensamento reflexivo, ainda há aprendizes que precisam entender melhor o conceito de seu uso e sua aplicabilidade. Assim, é de imensa importância que o trabalho de formação pré-serviço e continuada traga oportunidades para que os professores possam, cada vez mais, entender e utilizar as tecnologias em prol do ensino e aprendizagem.

Entendemos que, para que haja suficientes oportunidades de aprendizagem envolvendo novas tecnologias dentre os jovens do ensino fundamental e médio, há a necessidade de uma formaçáo inicial e continuada melhor estruturada e conscientizada para formaçáo de professores letrados digitalmente e motivados a aplicar esse conhecimento no dia a dia de suas salas de aulas.

Objetivamos continuar pesquisas sobre este escopo para entender melhor qual o caminho mais eficaz a ser construído pelos professores formadores, que paradigmas precisam ser revistos, qual a mediaçáo mais adequada a ser oferecida e quais alternativas podem ser usadas para que a prática e uso de instrumentos relacionados com novas tecnologias se façam presentes no ensino e aprendizagem em geral.

\section{THE DEVELOPMENT OF REFLEXTIVE THINKING IN ONLINE ACTIVITIES AND THE INICIAL TRAINING OF LANGUAGE TEACHERS}

- ABSTRACT: Our objective in this article is to address, firstly, principles related to information and communication technologies (ICT) in education and $21^{1^{t}}$ century learning, focusing on computer literacy, the importance of ICT in initial training of language teachers and the development 
of reflective thinking in the online context. After considering some theoretical assumptions, we will present an action research conducted in a Federal University in the discipline of Teaching Methodology for English for Specific Purposes. Finally, we present the results of the analysis of data collected through three instruments, during a semester of online activities in the discipline mentioned above, and our consideration of ICT applied to language teaching and teacher training.

- KEYWORDS: Information and communication technologies in education. $21^{t}$. century learning. Reflective thinking. Initial training of language teachers.

\section{REFERÊNCIAS}

BORAWSKI, C. Beyond the book: literacy in the digital age. The Journal of the Association for Library Service to Children, Chicago, v.7, n.3, p.43-53, Winter 2009.

BRASIL. Lei no 9394/96, de 20 de dezembro de 1996. Lei de Diretrizes e Bases da Educaçáo Nacional. Estabelece as diretrizes e bases da educação nacional. Diário Oficial, Brasília, 1996. Disponível em: <http://www.planalto.gov.br/ccivil_03/leis/L9394.htm>. Acesso em: 23 set. 2016.

COSTA, E. G. M. Práticas de letramento crítico na formação de professores de línguas estrangeiras. Revista Brasileira de Linguística Aplicada, Belo Horizonte, v. 12, n. 4, p. $911-$ 932, 2012.

CRAPOTTA, J.; GARCIA, J. S. Models of telecollaboration (2): cultura. In: O'DOWD, R. (Ed.). Online intercultural exchange: an introduction for foreign language teachers. Cromwell Press Ltd: Great Britain, 2007. p. 62-84.

DEWEY, J. How We think. Boston: Health and Company, 1993.

DUDLEY-EVANS, T.; ST JOHN, M. J. Developments in English for specific purposes: a multi-disciplinary approach. United Kingdom: Cambridge University Press, 1998.

EDWARD, L. Advantages and disadvantages of Mind Maps. 2011. Disponível em: <http:// iqmindbrainlibrary.com/aboutthinking/advantages-and-disadvantages-of-mind-maps/>. Acesso em: 15 jan. 2016.

EGBERT, J. Mediating the digital divide in CALL classrooms: promoting effective language tasks in limited technology contexts. ReCALL, Cambridge, v.16, n.2, p.280-291, 2004.

FELIX, U. The unreasonable effectiveness of CALL: What have we learned in two decades of research? ReCALL, Cambridge, v. 20, n. 2, p. 141-161, 2008.

FIGUEIREDO, C.A. Implementando atividades de leitura crítica em uma pesquisa de base etnográfica. The specialist, v. 24, n. 2, p. 177-199, 2003. 
FREITAS, M. T. Letramento digital e formação de professores. Educaçáo em Revista, Belo Horizonte, v.26, n.3, p.335-352, 2010.

GODDARD, M. What do we do with these computers? reflections on technology in the classroom. Journal of Research on Technology in Education, Philadelphia, v.35, n.1, p.1926, 2002.

HONEY, M. Testimony and statement for the record of Margaret Honey. Educational Development Center, Waltham, 2001. Disponível em: <http://cct.edc.org/sites/cct.edc.org/ files/publications/testimony_lhe01.pdf>. Acesso em: 27 set. 2016.

JAUREGI, K. Virtual interaction through video-web communication: a step towards enriching and internationalizing language learning programs. ReCALL, Cambridge, v.20, n.2, p.183207, 2008.

JORDÃO, C.; FOGAÇA, F. C. Ensino de inglês, letramento crítico e cidadania: um triângulo amoroso bem-sucedido. Línguas e Letras, Cascavel, v.8, n.14, p.79-105, 2007.

KERELUIK, K. et al. What Knowledge Is of Most Worth: Teacher Knowledge for 21st Century Learning. Journal of Digital Learning in Teacher Education, Philadelphia, v. 29, n. 4, p. 127-140, 2013.

KTORIDOU, D.; ETEOKLEOUS-GRIGORIOU, N. Developing digital imigrant's computer literacy: the case of unemployed women. Campus-Wide Information Systems, Bingley, v.28, n.3, p.154-163, 2011.

LÉVY, P. A inteligência coletiva: por uma antropologia do ciberespaço. São Paulo: Loyola, 1998.

MARZARI, G. Q.; LEFFA, V. J. O letramento digital no processo de formação de professores de línguas. Tear: Revista de Educação Ciência e Tecnologia, Canoas, v. 2, n. 2, 2013.

MIGUELA, A. D. Models of Telecollaboration (3): eTwinning. In: O’DOWD, R. (Ed.). Online intercultural exchange: an introduction for foreign language teachers. Trowbridge: Cromwell Press, 2007. p. 85-104.

O'DOWD, R.; RITTER, M. Understanding and working with Failed Communication in Telecollaborative Exchanges. CALICO Journal, San Marcos, v. 23, n. 3, p. 623-642, 2007.

PAYTON, S.; HAGUE, C. Digital literacy in practice: case studies of primary and secondary classrooms. Slough, UK: Futurelab, 2010.

POORE, M. Digital literacy: human flourishing and collective intelligence in a knowledge society. Literacy Learning: the Middle Years, Norwood, AU, v.19, n.2, p.20-26, 2011.

PORTAL HIPERTEXTO. Mapas mentais ou mapas conceituais. Disponível em: <http:// www.hipertexto.latec.ufrj.br/artigos-tecnicos/89-mapas-mentais>. Acesso em 04 fev. 2016. 
SAADI, M. L. K. View from Bangladesh: the new literacy. Ubiquity, v.2002, July 2009. Disponível em: <http://ubiquity.acm.org/article.cfm?id=763771>. Acesso em: 18 set. 2016.

SANTOS, L. I. S.; CICHELERO, M. Inclusão do letramento digital na formação continuada de docentes de língua inglesa: algumas contribuiçôes. Polifonia, Cuiabá, MT, v. 19, n.25, p.197-222, jan./jul., 2012.

SHIRKHANI, S.; FAHIM, M. Enhancing critical thinking in foreign language learners. Procedia: Social and Behavioral Sciences, v.29, p.111-115, 2011. Disponível em: <http:// www.sciencedirect.com/science/article/pii/S1877042811026759>. Acesso em 18 set. 2016.

THIOLLENT, M. Metodologia da pesquisa-ação. 2.ed. São Paulo: Cortez, 1986.

THORNE, S. L.; PAYNE, J. S. Evolutionary trajectories, Internet-mediated expression, and language education. CALICO Journal, San Marcos, v.22, p.371-397, 2005.

WARLICK, F. D. Redefining literacy for the 21st century. Santa Barbara, CA: Linworth Publishing, 2005.

Recebido em 04/02/2016

Aprovado em 29/07/2016 
